\title{
Waking OA's 'Slumbering Giant": The University's Mandate To Mandate Open Access
}

\author{
Stevan Harnad \\ Canada Research Chair in Cognitive Sciences \\ Université du Québec à Montréal \\ \& \\ School of Electronics and Computer Science \\ University of Southampton
}

SUMMARY: Universities (the universal research-providers) as well as research funders (public and private) are beginning to make it part of their mandates to ensure not only that researchers conduct and publish peer-reviewed research ("publish or perish"), but that they also make it available online, free for all. This is called Open Access (OA), and it maximizes the uptake, impact and progress of research by making it accessible to all potential users worldwide, not just those whose universities can afford to subscribe to the journal in which it is published. Researchers can provide OA to their published journal articles by self-archiving them in their own university's online repository. Students and junior faculty - the next generation of research providers and consumers -- are in a position to help accelerate the adoption of $O A$ self-archiving mandates by their universities, ushering in the era of universal $O A$.

\section{Principles of Open Access}

What is Open Access (OA)? OA is free online access.

OA comes in two forms: (1) the generic form, free online access itself, also called "gratis" OA; and (2) free online access plus certain re-use rights, granted with certain Creative Commons Licenses, also called "libre" OA. This essay is only about gratis OA. First things first.

Open Access to What? The primary target of the global OA movement is the 2.5 million articles published yearly in the world's 25,000 peer-reviewed research journals, across all scholarly and scientific disciplines, all institutions, and all languages.

Because of the cost of journal subscriptions, no institution can afford to subscribe to all journals; most institutions can only afford to subscribe to a small fraction of them. The online medium has made it possible to provide access to all journal articles, for all wouldbe users worldwide, rather than just those whose institutions can afford the subscription or license tolls.

The reason research journal articles are OA's primary target is that they are all, without exception, author give-aways, written exclusively for research usage, not for royalty income. Although some scholarly books too may be intended as author give-aways, these 
are currently the exception rather than the universal rule. Hence OA's focus on research journal articles. Again, first things first.

Why OA? The purpose of providing OA is to maximize the uptake, usage, applications and impact of all research output. OA has been repeatedly demonstrated to increase usage and citations of articles in all disciplines.

How to Provide OA? There are two roads to OA, "Green" and "Gold":

Authors take the "Green Road" to OA if they publish their article in a conventional journal and also "self-archive" its peer-reviewed final draft online, free for all (this is also called "Green OA"). Authors take the "Golden Road" to OA if they publish their article in an "OA journal" that makes its online edition free for all (this is also called "Gold OA").

As most journals today are not Gold OA journals, and as all authors can provide Green OA self-archiving, this essay is only about Green OA. First things first. Eventually universal Green OA self-archiving may result in subscription cancellations that make the subscription model of cost-recovery unsustainable, inducing journals to convert to Gold OA publishing. Publication costs will then no longer be paid for by institutional subscription fees for incoming journals but by article peer review fees paid for out of the instituitonal subscription cancellation savings.

But universal Gold OA is still far away, whereas universal Green OA is within reach, so this essay is only about Green OA: First things first.

How to Provide Green OA? Authors can make the peer-reviewed final drafts of articles accepted for publication free online by depositing them in their institutional repository.

An institutional repository (IR) is a database that universities and research institutions provide for their authors. It is compliant with the Open Archives Initiative (OAI) Protocol for Metadata Harvesting, which means that all OAI-compliant IRs are interoperable: the metadata for all their deposited articles are harvestable and searchable as if they had all been deposited in one global virtual archive. The first free, open source software for creating OAI-compliant OA IRs - EPrints -- was created in 2000 (Tansley \& Harnad 2000) specifically for the purpose of allowing all researchers and institutions to provide OA to their research output. EPrints is now used worldwide and has many emulators.

Where to Provide Green OA? In addition to distributed local institutional repositories (IRs) there are also central repositories (CRs), which may be based on content in a particular discipline, or from a particular country. Authors can deposit directly in CRs too (and some of them, such a ArXiv, are older than IRs), but as the institutions are the universal research providers, and as the OAI protocol makes all OAI-compliant repositories interoperable, the natural locus of deposit for institutional research output is the institution's own IR. Then the metadata can be harvested or exported into whatever discipline-based or national CRs are desired. This essay is accordingly focused only on 
IRs: First things first.

When to provide Green OA? The point at which peer-reviewed research becomes useable by all researchers is the point at which a final peer-reviewed draft has been accepted for publication, and that is when it should be self-archiving in the author's IR.

In some fields (notable computer science, physics and economics), drafts are made OA even earlier - even before they have been peer-reviewed, revised and accepted for publication. These drafts are called "preprints," whereas peer-reviewed drafts are called postprints. OA's primary target is postprints. Preprints are welcome in IRs too, just as books are; but across most disciplines, the authors who wish to make their unrefereed drafts freely accessible online are still in the minority, just as authors who want to give away their books free online are still in the minority. So this essay focusses only on the exception-free generic case of peer-reviewed postprints, accepted for publication. First things first.

The Principles that have been sketched here will now be elaborated in the Practice section.

\section{Putting OA Principles into Practice}

My guess is that Open Access (OA) already sounds old hat to the current generation of students and junior faculty, and that they are puzzled more about why we are still talking about OA happening in the future, rather than in the distant past (as the 80's and 90's must appear to them!).

Well, today's students and junior faculty are right to be both puzzled and impatient, but let me try to explain why it has been taking so long. (I say "try" because I have to admit that I too am still profoundly perplexed by the slowness of OA growth, even after having lived through its maddeningly molluscan pace for nearly 2 decades now!) I will also try to suggest what students and junior faculty can do to help speed OA on its way to its obvious, optimal, and long overdue destination.

\section{What OA Is Not}

First, what is Open Access (OA)? OA is not about Open Source (OS) software -- i.e., it is not about making computer programs either open or free (although of course OA is in favor of and compatible with OS).

OA is not about Creative Commons (CC) Licensing either -- i.e., it is not about making all digital creations re-usable and re-publishable (although, again, OA is in favor of and compatible with CC licensing, and may eventually help make it universal for peerreviewed research).

Nor is OA about "freedom of information" or "freedom of digital information" in general. 
(That is much too broad and vague: OA has a very specific kind of information as its target.)

And, I regret to say, OA is not about helping users get or share free access to commercial audio or video products, whether analog or digital: OA is completely neutral about that. OA's target is only creator give-aways, not "consumer sharing" (though of course free user access webwide will be the outcome, for OA's special target content).

\section{What Is OA's Target Content?}

As already noted in the Principles section, OA's target content is the 2.5 million articles a year that are published in the planet's 25,000 peer-reviewed scholarly and scientific journals.

Eventually OA might also extend to some scientific and scholarly books (the ones that authors want to give away) and also to scholarly/scientific data (if and when the researchers that collected them are ready to give them away); it may also extend to some software, some audio and some video.

But the only content to which OA applies without a single exception today is peerreviewed journal articles. Those are the works that their authors always wrote just so they should be read, used, applied, cited and built upon (mostly by their fellow researchers, worldwide). This is called "research impact". These works were never written in order to earn their authors income from their sale (Harnad 1995; 2001/2003).

These special authors -- researchers -- never sought or received any revenue from the sale of their journal articles. Indeed, the fact that there was a price-tag attached to accessing their articles (a price-tag usually paid through institutional library subscriptions) meant that these researcher-authors, and research itself, were losing research impact, because subscriptions to these journals were expensive, and most institutions could only afford access to a small fraction of them.

\section{What Is OA?}

To try to compensate for these access barriers in the old days of paper, these special giveaway authors would provide supplementary access, by mailing free individual reprints of their articles, at their own expense, to any would-be user who had written to request a reprint. One must remember, though, how slow, expensive and inefficient it must have been to have to supplement access in this way, in light of what the web has since made possible: First, the possibility of requesting and sending eprints via email was an improvement, but the obvious and optimal solution was to put the eprint on the web directly, so any would-be user, webwide, could instantly access it directly, at any time.

And that is the essence of OA: free, immediate, permanent, webwide access to peerreviewed research journal articles: give-away content -- written purely for usage and impact, not for sales revenue -- finding, at last, the medium in which it can be given 
away, free for all, globally, as it was always destined to be.

\section{OA = Gold OA or Green OA}

Some readers may have thought that OA was something else: Another form of publishing, perhaps? with the author-institution paying to publish the article rather than the user-institution paying to access it? That is OA journal publishing. But OA itself just means: free online access to the article itself.

As noted in the Principles section, there are two distinct ways an author can provide free online access to his own research article: One is by publishing it in an OA journal (this is called the "golden road" to OA, or simply "Gold OA"; Harnad et al. 2004) and the other is by publishing it in a conventional subscription journal, but also self-archiving a supplementary version, free for all, on the web (this is called the "green road" to OA, or simply "Green OA"; Harnad 2001; 2007a).

\section{OA $\neq$ Gold OA Only (or even Primarily)}

Gold OA publishing is probably what peer-reviewed journal publishing will eventually settle on (Harnad 2007a). But for now, only about $\underline{4000}$ of the $\underline{25,000}$ journals are Gold $\mathrm{OA}$, and the majority of the most important journals are not among that 4000 .

Moreover, most of the potential institutional money for paying for Gold OA is currently still tied up in each university's ongoing subscriptions to non-OA journals. So if Gold OA is to be paid for today, extra money needs to be found to pay for it (most likely by redirecting it from already-insufficient research funds).

Yet what is urgently needed by research and researchers today is not more money to pay for Gold OA, nor a conversion to Gold OA publishing, but OA itself.

And 100\% OA can already be provided by authors -- through Green OA self-archiving -virtually overnight.

It has therefore been a big mistake -- and is still one of the big obstacles slowing progress toward OA -- to imagine that OA means only, or primarily, Gold OA publishing.

\section{The "Subversive Proposal"}

It was in 1994 that the explicit "subversive proposal" was first made that if a supplementary copy of every peer-reviewed journal article were self-archived online by its author, free for all, as soon as it was published (as some authors in computer science and physics had already been doing for years), then we could have (what we would now call) $100 \%$ (Green) OA virtually overnight (Harnad 1995).

Yet that magic night has not arrived -- not then, in 1994, not in the ensuing decade and a half, and not yet today. Why not? 


\section{"Zeno's Paralysis"}

There are at least 34 reasons why it has not yet happened, all of them psychological, and all of them groundless. The syndrome even has a name: "Zeno's Paralysis" (Harnad 2006):

"I worry about self-archiving my article because it would violate copyright..." or "because it would bypass peer review..." or "because it would destroy journals..." or "because the online medium is not reliable..." or "because I have no time to self-archive..."

Meanwhile, evidence (demonstrating the obvious) was steadily growing that making your article OA greatly increases its usage and impact (Lawrence 2001; Harnad \& Brody 2004; Hajjem et al. 2005; Brody et al 200):

\section{Open Access increases citations}

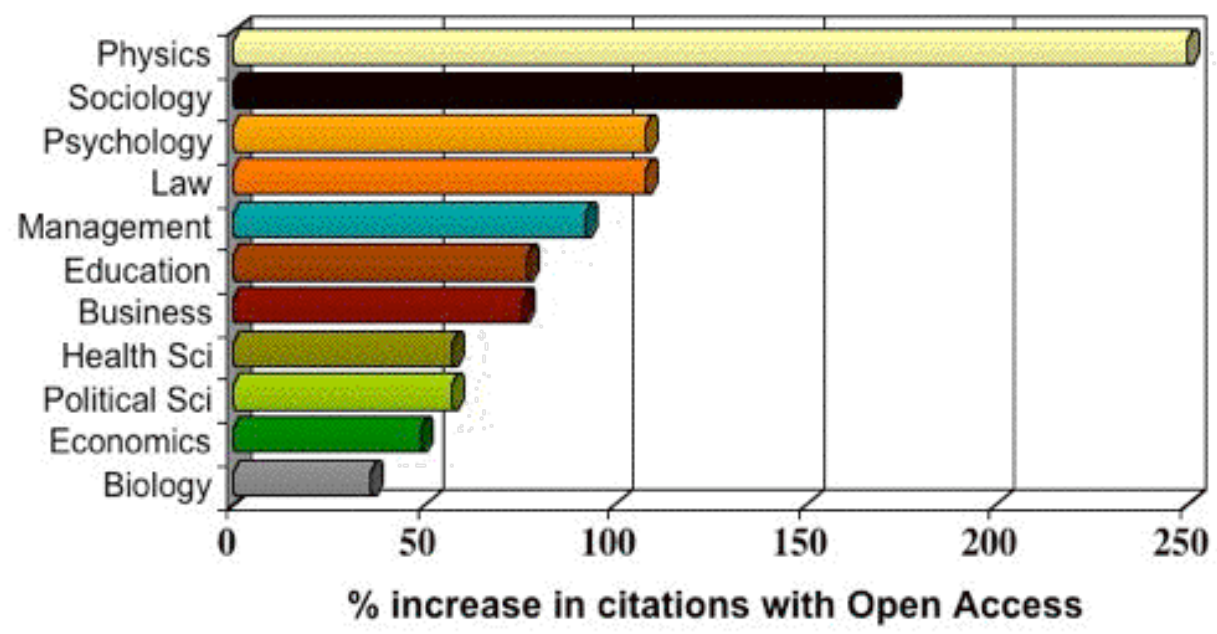

Range $=36 \%-200 \%$

(Data: Brody \& Harnad 2004; Hajjem et al.

2005)

Yet still most authors' fingers $(85 \%)$ remained paralyzed. The solution again seemed obvious: The cure for Zeno's Paralysis was a mandate from authors' institutions and funders, making it official policy that it is not only permissible for their employees and fundees to self-archive, but that it is expected of them, as a crucial new part of the process of doing research and publishing their findings in the online era. 


\section{"Publish or Perish: Self-Archive to Flourish!"}

The first explicit proposals to mandate OA self-archiving began appearing at least as early as 2000. Recommendations for institutional and funder Green OA self-archiving mandates were already in the Self-Archiving FAQ even before it was renamed the BOAI Self-Archiving FAQ in 2002; the same recommendations were also in the OSI EPrints Handbook. But these recommendations at first went unheeded. Not accidentally, the first officially adopted self-archiving mandate was that of the School of Electronics and Computer Science at the University of Southampton in 2002-2003, and it soon brought palpable benefits:

The G-factor International University Ranking measures the importance of universities as a function of the number of links to their websites from the websites of other leading international universities. Copyright Peter Hirst, 2006.

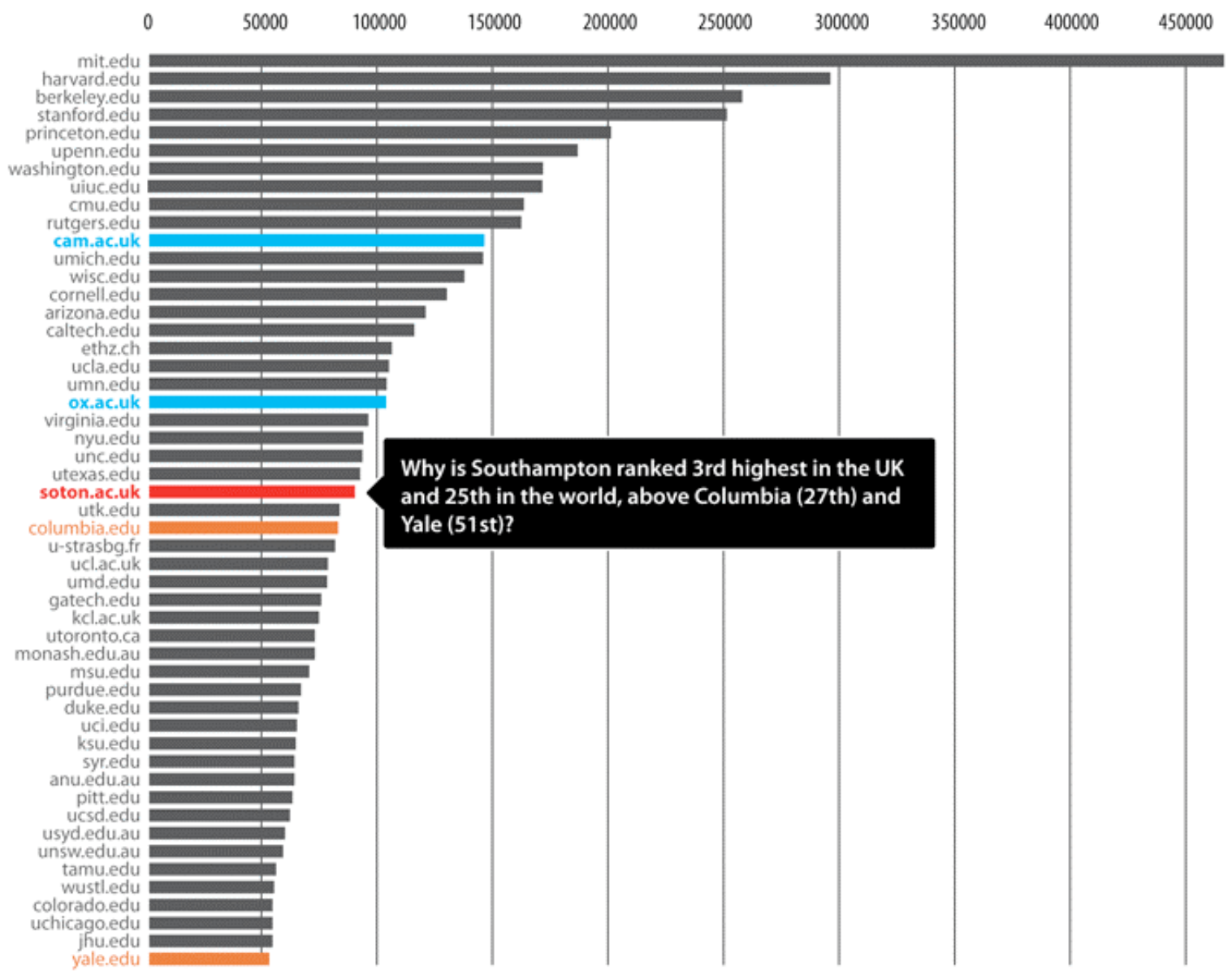

Why only Southampton? Don't blame the publishers: Since 2003, 97\% of 10,000 registered journals have already officially endorsed self-archiving in some form -- $63 \%$ for the final refereed draft (Berners-Lee et al 2005): 
Search List | List of publishers | More information | Summary Statistics | Journal Policies - Summary Statistics So Far

Current Journal Tally: $97 \%$ Green!

FULL-GREEN = Postprint, PALE-GREEN = Preprint, GRAY = neither yet

Total number of publishers registered at ROMEO to date: 523

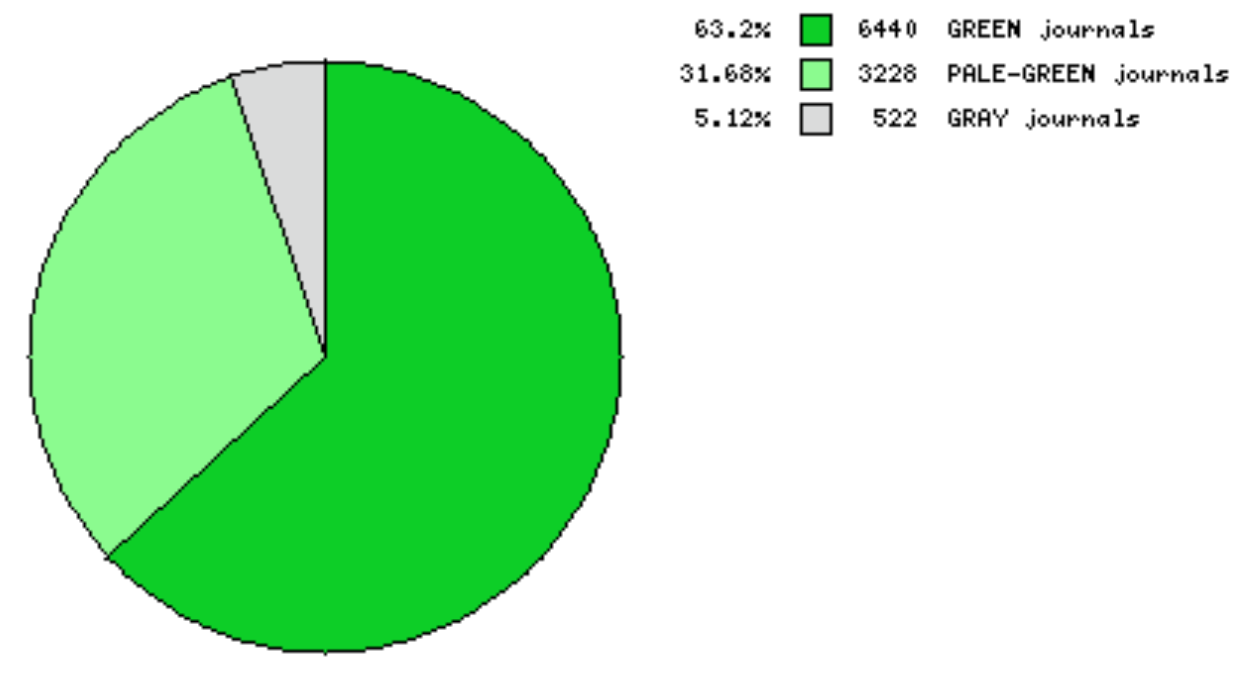

Apparently, however, even the blessing of most journals has not proved enough to set researchers' fingers onto motion: Alma Swan's surveys of authors' attitudes toward OA and OA self-archiving mandates -- across disciplines and around the world -- have consistently found that although authors are in favor of OA, most will not self-archive until and unless it is mandated by their universities and/or their funders. If self-archiving were mandated, however, $95 \%$ of authors state that they would comply, over $80 \%$ of them stating they would comply willingly (Swan 2005). 


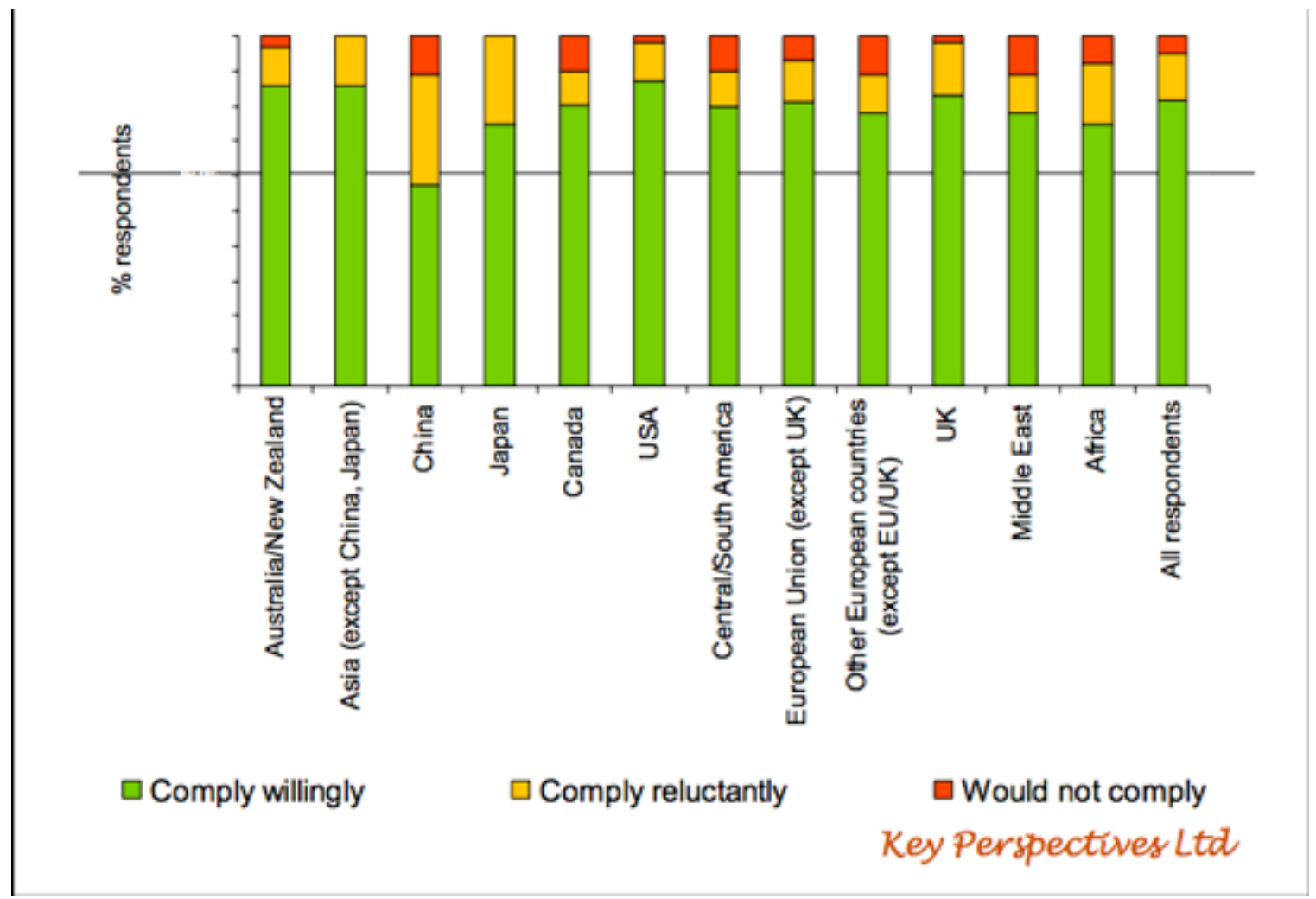

Arthur Sale's (2006) analyses of what authors actually do with and without a mandate have since confirmed that if unmandated, self-archiving in institutional repositories hovers at around $15 \%$ or lower, but with a mandate it approaches $100 \%$ within about 2 years: 


\section{University of Tasmania +Repository -Incentive -Mandate \\ Green line: total annual output \\ Red line: proportion selfarchived}

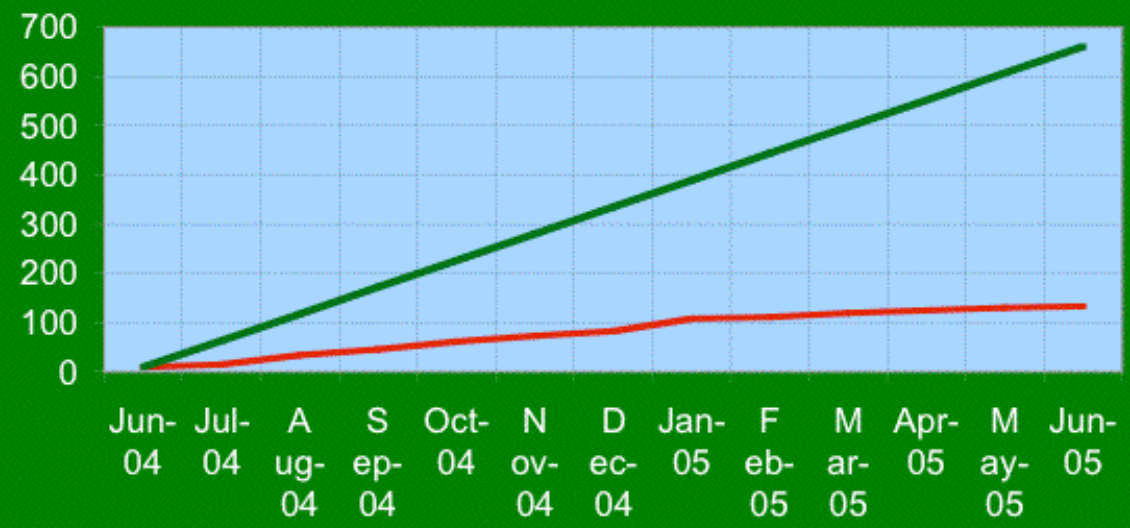

Actual

documents

DEST

publication

Data courtesy of Arthur Sale 


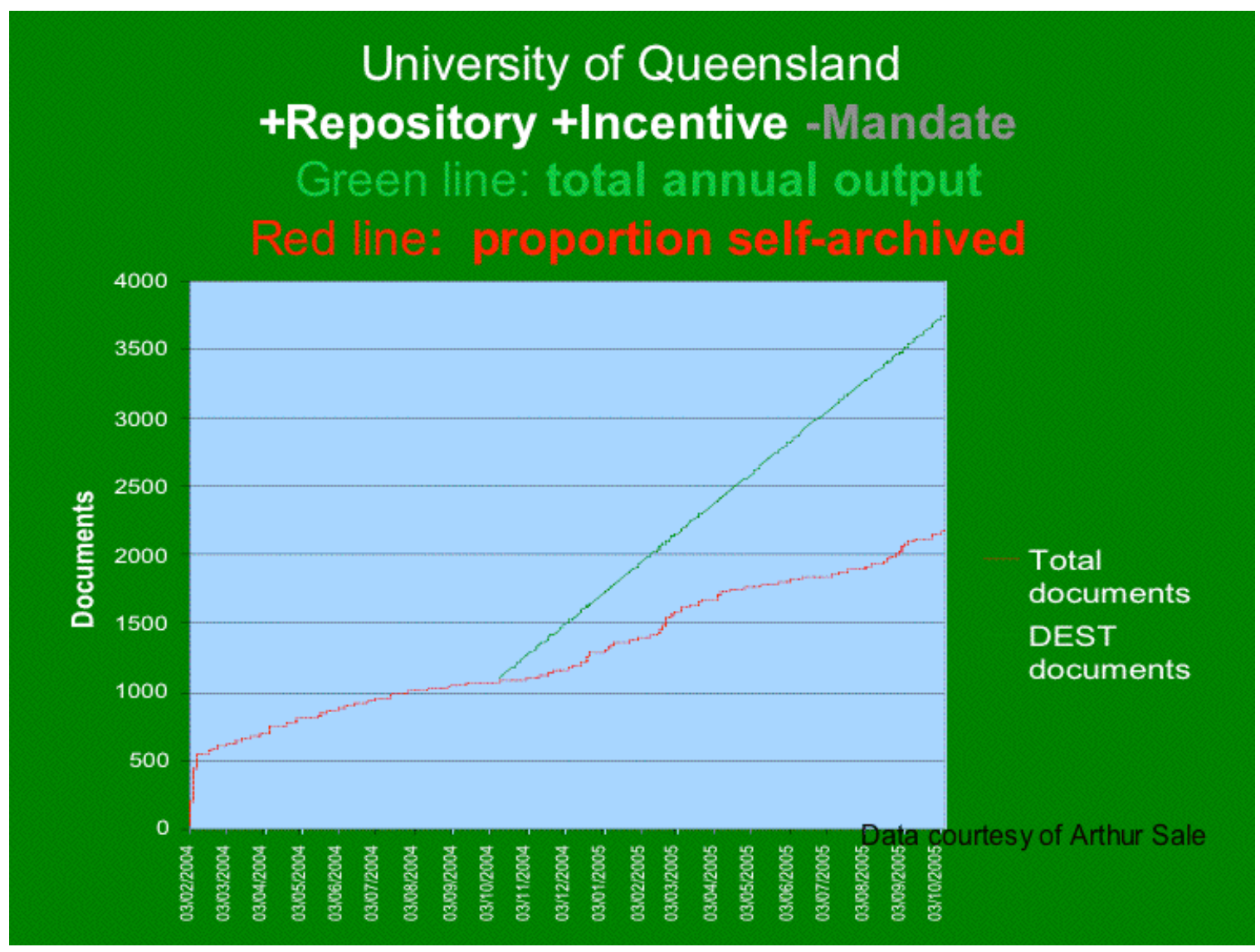




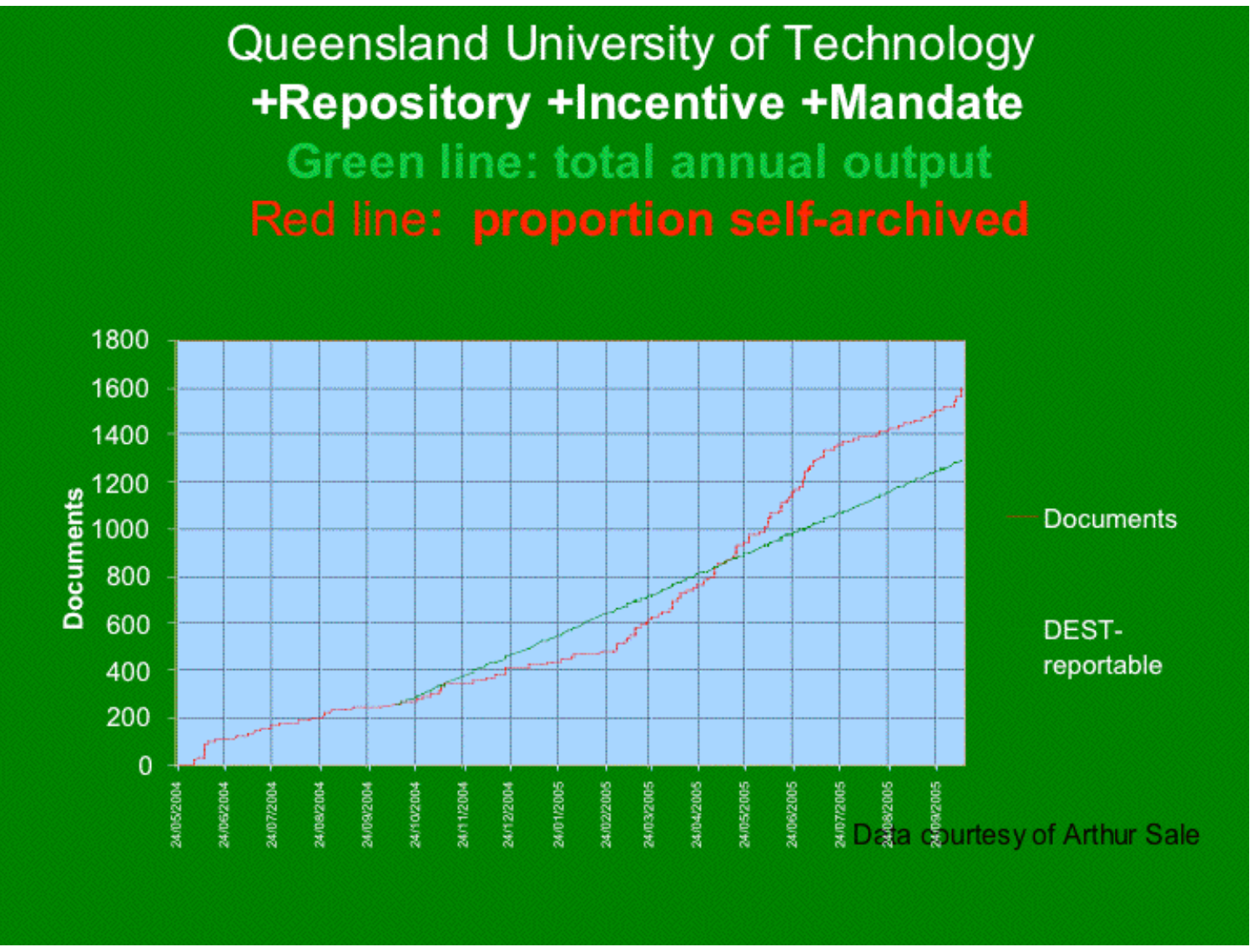

\section{What Students and Junior Faculty Can Do to Hasten the Optimal and Inevitable but Long Overdue Outcome:}

To date, 76 Green OA self-archiving mandates have been adopted worldwide, and 14 more have been proposed. Some of those mandates (such as that of NIH in the US,

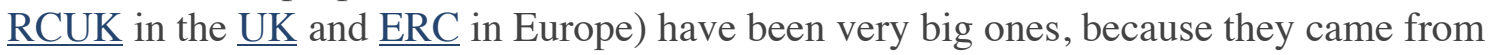
research funders (35). Individual university and departmental OA mandates are necessarily smaller in the volume each covers, but this does not explain why they are still so few (41). Even though virtually all research originates from universities, not all of it is funded, and universities share with their own researchers and students the benefits of showcasing and maximizing the uptake of their joint research output. Among the proposed mandates, two are very big multi-university proposals (one for all 791 universities in the 46 countries of the European University Association and one for all the universities and research institutions of Brazil), but those mandate proposals have yet to be adopted. The recent Harvard, Stanford and MIT mandates, may now help rouse the c. 10,000 universities in the rest of the world (as the original Southampton mandate was evidently unable to do).

The world's universities are indeed OA's "slumbering giant." They have everything to gain from mandating OA, but they are being extremely slow to realize it and to do 
something about it. Unlike today's students and junior faculty, they have not grown up in the online age, and to them the online medium's potential is not yet as transparent and natural as it is to the current generation. By making their voices and wishes heard, students and junior faculty can help awaken their university's sense of its own need for $\mathrm{OA}$, as well as its awareness of the benefits of OA, and the means of attaining them:

1. OA Self-Archiving Begins At Home: First, let the professors and administration of your university know that you need and want (and expect!) research articles to be freely accessible to you on the web. This means the entire research output of your own university to begin with (and not just the fraction of its total research output that your university can afford to buy-back in the form of journal subscriptions!). That way students will know what research is being done at their own university, whom to study with, whom to do research projects with; OA will even help them select a university for undergraduate or graduate study in the first place. Junior faculty will also discover whom to collaborate with, and prospective faculty and recruits from other universities can be better informed about where each university's respective strengths lie.

\section{Self-Archive Unto Others As You Would Have Them Self-Archive Unto You:} Second, point out the "Golden [or rather Green!] Rule" to the senior faculty and administration of your university: If each university self-archives its own research output, this will make it possible for its students to access the research output of all other universities (and not just the fraction of the total research output of other universities that their own university can afford to buy-in in the form of journal subscriptions!). That way they can use any published research findings in their own studies and research projects. Far more important, it will also make it possible for all researchers, at all universities (including your own), to access all research findings, and to use and apply them in their own research and teaching, thereby maximizing research productivity and progress for the global university community worldwide -- as well as for the tax-paying public that funds it all, the ones for whose benefit the research is being conducted (Harnad 2003/2004; Harnad et al. 2008).

It is very important, however, to get both the rationale and priorities for OA straight! The (successful) lobbying for the NIH self-archiving mandate was based in part on a premise that may have gone over well with politicians, and perhaps even with voters, but if thought through, it would not be able to stand up to close scrutiny. The slogan had been: "We need to have OA so that taxpayers can have access to health research findings that they themselves paid for." True. And sounds good. But how many of the annual 2.5 million peer-reviewed research journal articles published every year in the 25,000 journals across all disciplines does that really apply to? How many of those highly specialized articles are taxpaying citizens likely ever to want (or even be able) to read! Most of them are not even relevant or comprehensible to undergraduate students or specialists from other fields.

\section{Peer-To-Peer Access}

So the overarching rationale for OA cannot be public access (though of course public 
access comes with the territory, with OA). It has to be peer-to-peer access. The peers are the research specialists worldwide by and for whom most of the peer-reviewed literature is written. Postgraduate students are entering this peer community; undergraduates are on the boundaries of it. But the general tax-paying public (welcome as they are) has next to no interest in most of it at all.

By the very same token, it will not be possible to persuade university researchers and administrators that OA to the peer-reviewed research literature needs to be mandated because students have a burning need and desire to read it all! Students do benefit from OA, to be sure, but that cannot be the primary rationale for OA.Peer-to-peer (i.e., researcher-to-researcher) access is what has to be stressed. It is researchers worldwide who are today being denied access to the research findings they need in order to advance their research for the benefit of us all -- for the benefit of present and future students for whom the findings will be digested and integrated in textbooks, for the benefit of junior and senior faculty, who are the primary intended users of the research, and for the benefit of the general public, for whom it is hoped that some of the findings will eventually be applied in the form of technological advances and medicines for illnesses, as well as intellectual and cultural food for thought.

So it is daily, weekly, monthly research impact that is needlessly being lost, cumulatively, while we keep dragging our feet about providing OA. That's what students need to stress to their professors and administration; that's what junior faculty need to stress to senior faculty and administration: all those research findings that could not be used and applied and built upon because they could not be accessed by all or even most of their potential users, because it simply costs too much to subscribe to all or most of the journals in which they were published.

\section{Updating the Academic Mandate for the Online Era}

It is important to point out also that $O A$ policies always fail if they are merely "recommendations" or "requests," even if "strongly encouraged." This was already heralded by Swan's (2005) surveys, confirmed by Sale's (2006) actual outcome studies, and brought home particularly dramatically by the total failure of NIH's initial nonmandatary policy, and the almost-immediate success as soon as it was upgraded to a mandate.

The only thing that will embolden and motivate all researchers to self-archive is selfarchiving mandates. "Mandate" is not a bad word. It does not mean "coercion" or punishment. It is all carrots, not sticks (Shadbolt et al. 2006; Brody et al 2007). University faculty have a mandate to teach, and test, and give marks. They also have a mandate to do research, and publish (or perish!). If they teach well and do good research, they earn promotions, salary increases, tenure, research funding, prizes. OA enhances the chances of good work being recognized, credited and rewarded.

The three main reasons researchers do not self-archive until and unless it is mandated are (1) worries that it might be illegal, (2) worries that it might put acceptance by their 
preferred journal at risk, and (3) worries that it might take a lot of time. Hence the reason they need Green OA mandates from their institutions and funders is not in order to force them to self-archive but in order to reinforce them to self-archive, making it official policy that it is not only okay for them to deposit their research article output in their institution's repository, but that it is expected of them, well worth the few minutes worth of extra keystrokes per paper (Carr \& Harnad 2005), and an important component in both enhancing and assessing their research impact.

\section{Mandates and Metrics}

Hence it is not so much a matter of universities adopting a new "Green OA self-archiving mandate" for their faculty, but of adapting and extending their existing, traditional mandate to do research and publish their findings. OA self-archiving is a natural adaptation to the PostGutenberg Galaxy (Harnad 1991) and its technical potential (just as we adapted to reading and writing, printing, libraries and photocopying). It is no longer enough to just conduct, write up, and publish research: The write-up has to be selfarchived online too, so it can have its full impact, webwide. And the carrots are already there to reward doing it: Faculty are already evaluated on how well they fulfill their research performance mandate not only by counting their publications, but by assessing their impact -- for which one of the most important metrics is how much that research is accessed, taken up, used, built upon, applied and cited by further research. Citation counts are among the existing metrics that OA has been shown to increase, and OA itself is generating many new metrics of research performance, rich and diverse ones that have the potential to make research assessment more reliable and valid (Harnad et al 2003; Harnad 2007b, 2008).

A self-archiving mandate is not unlike the increasingly widespread policy that students -as a part of their own mandate as students - in place of submitting their work for evaluation and grading on paper, submit it online (as most of them already do!). The difference is that a self-archiving mandate is even better than that for faculty, because in thus making their work OA they will actually increase their "grades."

In short, it's a win/win/win situation for universities, researchers and students -- if only your university gets around, at long last, to fast-forwarding us all to the optimal and inevitable: by mandating Green OA self-archiving. Rather than be puzzled and impatient that they have not done it already, we should all provide a strong show of support for their doing it now. Be ready with the answers to the inevitable questions about how and why (and when and where). And beware, the 34-headed monster of "Zeno's Paralysis" is still at large, guarding the access routes to the slumbering giant, and growing back new heads the minute you lop one off...

\section{REFERENCES}

Berners-Lee, T., De Roure, D., Harnad, S. and Shadbolt, N. (2005) Journal publishing and author self-archiving: Peaceful Co-Existence and Fruitful Collaboration. 


\section{http://eprints.ecs.soton.ac.uk/11160/}

Brody, T., Harnad, S. and Carr, L. (2006) Earlier Web Usage Statistics as Predictors of Later Citation Impact. Journal of the American Association for Information Science and Technology (JASIST) 57(8) pp. 1060-1072. http://eprints.ecs.soton.ac.uk/10713/

Brody, T., Carr, L., Gingras, Y., Hajjem, C., Harnad, S. and Swan, A. (2007) Incentivizing the Open Access Research Web: Publication-Archiving, Data-Archiving and Scientometrics. CTWatch Quarterly 3(3). http://eprints.ecs.soton.ac.uk/14418/

Carr, L. and Harnad, S. (2005) Keystroke Economy: A Study of the Time and Effort Involved in Self-Archiving. http://eprints.ecs.soton.ac.uk/10688/

Hajjem, C., Harnad, S. and Gingras, Y. (2005) Ten-Year Cross-Disciplinary Comparison of the Growth of Open Access and How it Increases Research Citation Impact. IEEE Data Engineering Bulletin 28(4) pp. 39-47. http://eprints.ecs.soton.ac.uk/11688/

Harnad, S. (1978) Editorial. Behavioral and Brain Sciences. http://www.ecs.soton.ac.uk/ harnad/Temp/Kata/bbs.editorial.html

Harnad, S. (1990) Scholarly Skywriting and the Prepublication Continuum of Scientific Inquiry Psychological Science 1: 342 - 343 http://cogprints.org/1581

Harnad, S. (1991) Post-Gutenberg Galaxy: The Fourth Revolution in the Means of Production of Knowledge. Public-Access Computer Systems Review 2 (1): 39 - 53 http://cogprints.org/1580/

Harnad, S. (1995) Universal FTP Archives for Esoteric Science and Scholarship: A Subversive Proposal. In: Ann Okerson \& James O'Donnell (Eds.) Scholarly Journals at the Crossroads; A Subversive Proposal for Electronic Publishing. Washington, DC., Association of Research Libraries. http://www.arl.org/scomm/subversive/toc.html

Harnad, S. (1998/2004) The invisible hand of peer review. Nature [online] (5 Nov. 1998), and in Shatz, B. (2004) (ed.) Peer Review: A Critical Inquiry. Rowland \& Littlefield. Pp. 235-242. http://cogprints.org/1646/

Harnad, S (2001/2003) For Whom the Gate Tolls? http://cogprints.org/1639/ Published as: (2003) Open Access to Peer-Reviewed Research Through Author/Institution SelfArchiving: Maximizing Research Impact by Maximizing Online Access. In: Law, Derek \& Judith Andrews, Eds. Digital Libraries: Policy Planning and Practice. Ashgate Publishing 2003.

Harnad, S. (2001) The Self-Archiving Initiative. Nature 410: 1024-1025 http://cogprints.org/1640/

Harnad, S. (2003/2004) Back to the Oral Tradition Through Skywriting at the Speed of 
Thought. Interdisciplines. Retour a la tradition orale: ecrire dans le ciel a la vitesse de la pensee. Dans: Salaun, Jean-Michel \& Vendendorpe, Christian (dir). Le defi de la publication sur le web: hyperlectures, cybertextes et meta-editions. Presses de l'enssib. http://eprints.ecs.soton.ac.uk/7723/

Harnad, S. (2006) Opening Access by Overcoming Zeno's Paralysis, in Jacobs, N., Eds. Open Access: Key Strategic, Technical and Economic Aspects, chapter 8. Chandos. http://eprints.ecs.soton.ac.uk/12094/

Harnad, S. (2007a) The Green Road to Open Access: A Leveraged Transition. In: Anna Gacs. The Culture of Periodicals from the Perspective of the Electronic Age.

L'Harmattan. 99-106. http://eprints.ecs.soton.ac.uk/13309/

Harnad, S. (2007b) Open Access Scientometrics and the UK Research Assessment Exercise. In Proceedings of 11th Annual Meeting of the International Society for Scientometrics and Informetrics 11(1), pp. 27-33, Madrid, Spain. Torres-Salinas, D. and Moed, H. F., Eds. (2009) Scientometrics 79 (1) http://eprints.ecs.soton.ac.uk/17142/

Harnad, S. (2008) Validating Research Performance Metrics Against Peer Rankings. Ethics in Science and Environmental Politics 8 (11) doi:10.3354/esep00088 The Use And Misuse Of Bibliometric Indices In Evaluating Scholarly Performance http://eprints.ecs.soton.ac.uk/15619/

Harnad, S. \& Brody, T. (2004) Comparing the Impact of Open Access (OA) vs. Non-OA Articles in the Same Journals, D-Lib Magazine 10 (6)

http://eprints.ecs.soton.ac.uk/10207/

Harnad, S., Brody, T., Vallieres, F., Carr, L., Hitchcock, S., Gingras, Y, Oppenheim, C., Hajjem, C., \& Hilf, E. (2004) The Access/Impact Problem and the Green and Gold Roads to Open Access: An Update. Nature Web Focus.

http://www.nature.com/nature/focus/accessdebate/21.html

Harnad, S., Carr, L., Brody, T. \& Oppenheim, C. (2003) Mandated online RAE CVs Linked to University Eprint Archives. Ariadne 35.

http://www.ecs.soton.ac.uk/ harnad/Temp/Ariadne-RAE.htm

Harnad, S., Carr, L. and Gingras, Y. (2008) Maximizing Research Progress Through Open Access Mandates and Metrics. Liinc em Revista 4(2).

http://eprints.ecs.soton.ac.uk/16617/

Lawrence, S (2001) Online or Invisible? Nature 411 (6837): 521.

Sale, AHJ (2006) The acquisition of open access research articles. First Monday, 11 (10). http://eprints.utas.edu.au/view/authors/Sale, AHJ.html

Swan, Alma (2005). Open Access self-archiving: An introduction, 


\section{http://eprints.ecs.soton.ac.uk/11006/01/jiscsum.pdf}

Shadbolt, N., Brody, T., Carr, L. and Harnad, S. (2006) The Open Research Web: A Preview of the Optimal and the Inevitable, in Jacobs, N., Eds. Open Access: Key Strategic, Technical and Economic Aspects. Chandos.

Tansley, R. \& Harnad, S. (2000) Eprints.org Software for Creating Institutional and Individual Open Archives D-Lib Magazine 6 (10) http://www .dlib.org/dlib/october00/10inbrief.html\#HARNAD 